\title{
Explore Upper Limits of Bone Mineral Content And Density In Humans: A Study On Japanese Collegiate Sumo Wrestlers
}

Taishi Midorikawa ( $\square$ taishi@obirin.ac.jp)

J. F. Oberlin University

\section{Suguru Torii}

Waseda University

Megumi Ohta

Chukyo University

Shizuo Sakamoto

Waseda University

\section{Research Article}

Keywords: Bone mineral density, dual-energy X-ray absorptiometry, heavyweight athlete

Posted Date: November 1st, 2021

DOI: https://doi.org/10.21203/rs.3.rs-1001814/v1

License: (c) (i) This work is licensed under a Creative Commons Attribution 4.0 International License.

Read Full License 


\section{Abstract}

The purpose of this study was to explore the upper limit of total bone mineral content $(\mathrm{BMC}, \mathrm{kg})$ and bone mineral density (BMD, $\mathrm{g} / \mathrm{cm}^{2}$ ) in humans by estimating body composition of Sumo wrestlers. A total of 54 male college Sumo wrestlers were recruited for the study and assigned to 2 groups according to body weight (middleweight, 85-115 kg, $\mathrm{n}=23$ and heavyweight, $>115 \mathrm{~kg}, \mathrm{n}=31$ ). BMC, BMD, fat mass and lean soft tissue mass (LSTM) were measured using dual-energy X-ray absorptiometry (DXA) for the total and appendicular regions. Heavyweight Sumo wrestlers had significantly greater body weight, fat mass, and LSTM compared to middleweight Sumo wrestlers. Mean total BMC was significantly larger in heavyweight than middleweight Sumo wrestlers, respectively (The highest value was $4.16 \mathrm{~kg}$.). Total BMD was significantly higher in heavyweight compared to middleweight Sumo wrestlers (The highest value was $1.59 \mathrm{~g} / \mathrm{cm}^{2}$.), and was significantly correlated with body weight, but not with fat mass and LSTM. Based on the present and previous studies, the upper limit of total BMC and BMD in humans with $150 \mathrm{~kg}$ bodyweight might be around $5.0 \mathrm{~kg}$ and $1.60 \mathrm{~g} / \mathrm{cm}^{2}$.

\section{Introduction}

Sumo wrestlers have to weigh more than $100 \mathrm{~kg}$ in order to win a game. In general, although Sumo wrestlers could be considered obese, previous studies reported that the mean value of percent body fat using underwater weighting method and dual-energy X-ray absorptiometry (DXA) was not too high between 20 and $30 \%{ }^{1,2}$. Moreover, previous studies indicated that the average value of fat-free mass (FFM) in Sumo wrestlers was approximately $80 \mathrm{~kg}^{2}$ and the upper limit of FFM might approach $150 \mathrm{~kg}^{3}$. Thus, investigating body composition in Sumo wrestlers might lead to the appropriate knowledge of adaptation ability in humans.

FFM consists of various organ tissues. Skeletal muscle (SM) is the largest organ tissue ${ }^{4}$ and approximately $40 \%$ of FFM in adults ${ }^{5}$. It was reported that SM mass in college Sumo wrestlers with FFM of $79 \mathrm{~kg}$ was approximately $37 \mathrm{~kg}$ and about one and a half times compared to untrained college students with FFM of $53 \mathrm{~kg}$ (i.e. $25 \mathrm{~kg}$ ) 6 . In addition, the left ventricular end-diastolic dimension of Japanese professional Sumo wrestlers frequently exceeds the traditionally accepted upper limit of normal for the general population? ${ }^{7}$ Interestingly, the mass of liver and kidneys also in Sumo wrestlers (i.e. 2.4 and $0.5 \mathrm{~kg}$ ) was larger than controls (i.e. 1.4 and $0.3 \mathrm{~kg}$ ) ${ }^{6}$. These cases might be one of the adaptations for daily exercise training and diet for Sumo wrestling.

Currently, there is limited information about bone mineral contents (BMC: $\mathrm{kg}$ ) and bone mineral density (BMD: $\mathrm{g} / \mathrm{cm}^{2}$ ) in Sumo wrestlers, although bone is the third-largest organ tissue of FFM components. Since it is well known that the weight-bearing exercise may be more effective for increasing $\mathrm{BMC}$ and $\mathrm{BMD}^{8}$, it is hypothesized that heavier Sumo wrestlers could have a higher BMC and BMD. Therefore, the purpose of this study was to explore the upper limits of total BMC and BMD in humans by estimating body composition of Sumo wrestlers. 


\section{Methods}

Subjects

A total of 54 male college Sumo wrestlers were recruited for the study. Regular training ("Kei-ko") does not target specific muscles but is more of a whole-body exercise for proper balance. None of the subjects had a history of cardiovascular, endocrine, or orthopedic disorders, nor had they ever tested positive for anabolic steroids or taken any medication during the given measurement time. This study followed the guidelines of the Declaration of Helsinki, and the Ethical Committees of Waseda University and the National Institute of Health and Nutrition approved all procedures involving human subjects/patients. Written informed consent was obtained from all subjects before testing.

Anthropometry and dual-energy X-ray absorptiometry (DXA) measurements

Body weight was measured to the nearest $0.1 \mathrm{~kg}$ by using a digital scale (DC-320, TANITA Co. Ltd), with the subjects wearing only minimal clothing. Standing height was measured to the nearest $0.1 \mathrm{~cm}$ by using a stadiometer (YS-OA, AS ONE Co. Ltd). Body mass index was calculated as body weight in kilograms per square of standing height in meters $\left(\mathrm{kg} / \mathrm{m}^{2}\right)$. The percent of body fat was measured using DXA (Delphi A-QDR, Hologic Inc., Bedford, MA, USA; Version 12.4:3 Auto Whole Body Fan Beam). FFM was calculated from body weight and the percent of body fat.

Total and appendicular (i.e. arm and leg regions) BMC and BMD, fat mass, lean soft tissue mass (LSTM) were also measured using DXA. The whole body scan image was separated into discrete regions using DXA regional computer-generated default lines on the anterior planogram view with manual adjustments. The 'Head and Neck' region was defined as the area above the line connecting the bilateral acromions. The 'Arm' region was defined as the area distal to the line connecting the axilla and the glenohumeral joint space. The 'Leg' region was defined as the area distal to the line tangent to the ischium and the upper edge of the greater trochanter. The estimated coefficient of validation for DXA measurements from the test-retest analysis was determined to be $<1 \%$.

\section{Statistics}

All results are presented as means and standard deviations (SDs). A total of 54 subjects were assigned to 2 groups according to body weight of $115 \mathrm{~kg}$, which is the criteria of the international Sumo federation between middleweight (85-115 kg; $\mathrm{n}=23$ ) and heavyweight group ( $>115 \mathrm{~kg} ; \mathrm{n}=31$ ). The differences between the 2 groups were tested for significance using an unpaired t-test. Pearson's product-moment analysis was used to compare the relationships of body weight with the percentages of body fat and $\mathrm{BMC}$, and between each BMD (total, arms, and legs) and anthropometric parameters (body weight, fat mass, and LSTM) for all subjects. Statistical analyses were performed using SPSS for Windows (IBM SPSS version 27.0; SPSS Inc., Chicago, IL, USA). Differences were considered significant when the p-value was $<0.05$. 


\section{Results}

Heavyweight Sumo wrestlers had significantly higher and greater standing height, body weight, BMI, body fat percentage, FFM, fat mass, and LSTM by DXA compared to middleweight Sumo wrestlers (Table 1). While body weight was directly proportional to body fat percentage, it was inversely correlated with BMC percentage in all subjects (Figure 1). Mean total and appendicular BMC was significantly larger in heavyweight than middleweight Sumo wrestlers, respectively (Table 2). Total BMD was significantly higher in heavyweight compared to middleweight Sumo wrestlers, and was significantly correlated with body weight, but not with fat mass and LSTM (Table 2 and 3). Arms BMD was not different between both groups and was not associated with body weight, fat mass, and LSTM (Table 2 and 3 ). Legs BMD was significantly greater in heavyweight than middleweight Sumo wrestlers and was significantly correlated with body weight and LSTM (Table 2 and 3).

Table 1. Subject characteristics.

\begin{tabular}{lrr}
\hline & $\begin{array}{r}\text { Middle weight } \\
\mathrm{n}\end{array}$ & $=23$ \\
\hline Age (year) & $20 \pm 1$ & $\begin{array}{c}\text { Heavy weight } \\
\mathrm{n}=31\end{array}$ \\
Standing height $(\mathrm{cm})$ & $173.4 \pm 5.8$ & $19 \pm 1$ \\
Body weight $(\mathrm{kg})$ & $98.1 \pm 7.4$ & $130.4 \pm 5.3 *$ \\
BMI $\left(\mathrm{kg} / \mathrm{m}^{2}\right)$ & $32.7 \pm 2.9$ & $41.8 \pm 4.3 * *$ \\
Fat $(\%)$ & $23.3 \pm 3.4$ & $31.2 \pm 3.9 * *$ \\
Fat-free mass $(\mathrm{kg})$ & $75.1 \pm 5.2$ & $89.5 \pm 5.6 * *$ \\
Fat mass by DXA $(\mathrm{kg})$ & $23.5 \pm 4.4$ & $41.5 \pm 7.4 * *$ \\
Lean soft tissue mass by DXA $(\mathrm{kg})$ & $73.5 \pm 5.2$ & $87.2 \pm 5.1 * *$ \\
\hline
\end{tabular}

Middle weight vs. Heavy weight: ${ }^{*} \mathrm{p}<0.05,{ }^{* *} \mathrm{p}<0.01$.

Table 2. Total and regional bone mineral content and density. 


$\begin{array}{cc}\text { Middle weight } & \text { Heavy weight } \\ \mathrm{n}=23 & \mathrm{n}=31\end{array}$

Bone mineral content $(\mathrm{kg})$

Total

$3.17 \pm 0.29$

$3.49 \pm 0.32 * *$

Arm

$0.54 \pm 0.06$

$0.59 \pm 0.06 * *$

Leg

$1.16 \pm 0.11$

$1.28 \pm 0.13 * *$

Bone mineral dencity $\left(\mathrm{g} / \mathrm{cm}^{2}\right)$

\begin{tabular}{|c|c|c|}
\hline Total & $1.28 \pm 0.08$ & $1.33 \pm 0.09 *$ \\
\hline Arm & $0.99 \pm 0.07$ & $1.03 \pm 0.07$ \\
\hline Leg & $1.34 \pm 0.09$ & $1.41 \pm 0.11 *$ \\
\hline
\end{tabular}

Middle weight vs. Heavy weight: ${ }^{*} \mathrm{p}<0.05,{ }^{*} \mathrm{p}<0.01$

Table 3. Correlation coefficients between bone mineral density and body composition parameters.

\begin{tabular}{lccc}
\hline Sumo wrestlers $(\mathrm{n}=54)$ & Body weight & Fat mass & LSTM \\
\hline Bone mineral dencity $\left(\mathrm{g} / \mathrm{cm}^{2}\right)$ & & & \\
Total & $0.27 *$ & 0.24 & 0.23 \\
Arm & 0.25 & 0.23 & 0.23 \\
Leg & $0.29 *$ & 0.21 & $0.34 *$ \\
\hline
\end{tabular}

$* \mathrm{p}<0.05$. LSTM: lean soft tissue mass.

\section{Discussion}

The present study found that heavyweight collegiate Sumo wrestlers could have approximately $10 \%$ higher total BMC compared to middleweight Sumo wrestlers (Table 2). Moreover, the highest value of total BMC was $4.16 \mathrm{~kg}$ (2.9\% BMC to 143.6 body weight $\mathrm{kg}$ ) in the present study. According to the previous study in healthy Japanese adults, mean and 95th percentiles of total BMC was $2.5 \mathrm{~kg}$ and about $3.1 \mathrm{~kg}$ for the age group of 20-29 (140 males, mean body weight: $65.6 \mathrm{~kg}$ ) using DXA (QDR-2000, Hologic Inc. $)^{9}$, which is the same product as the present study. In addition, according to the previous study on competitive athletes, the mean total BMC is $4.32 \mathrm{~kg}$ in collegiate American football players (33 males, mean age: 22.3 years, mean bodyweight: $97.7 \mathrm{~kg}$ ) using the same product DXA (Hologic-WI, Hologic Inc. $)^{10}$. On the other hand, the inverse relationship between body weight and BMC percentage was observed in the present study (Figure 1). When the regression equation is applied in the case of having $200 \mathrm{~kg}$ body weight, BMC percentage and BMC would be $1.4 \%$ and $2.76 \mathrm{~kg}$, respectively. Based on the 
present and previous studies, it is indicated that total BMC is not easily increased in response to larger body weight, and the upper limit of total BMC in humans with $150 \mathrm{~kg}$ bodyweight might be around $5.0 \mathrm{~kg}$.

It has been well documented that weight-bearing physical activity has a positive effect on BMD ${ }^{8,12}$. In fact, an elite male soccer player (age 21.0 years, body weight: $77.8 \mathrm{~kg}$, total BMD: $1.23 \mathrm{~g} / \mathrm{cm}^{2}$ ) has approximately $10 \%$ higher value than controls (age 24.3 years, body weight: $76.5 \mathrm{~kg}$, total BMD: 1.12 $\mathrm{g} / \mathrm{cm}^{2}$ ) in case of using DXA (QDR-1000, Hologic Inc.) $)^{13}$. The above-mentioned previous study in healthy Japanese adults reported that the mean total BMD was $1.12 \mathrm{~g} / \mathrm{cm}^{2}$ for the age group of 20-299. Compared to this BMD value of the previous study, middle (body weight: $98.1 \mathrm{~kg}$, total BMD: $1.28 \mathrm{~g} / \mathrm{cm}^{2}$ ) and heavy (body weight: $130.4 \mathrm{~kg}$, total BMD: $1.33 \mathrm{~g} / \mathrm{cm}^{2}$ ) weight Sumo wrestlers in the present study has about $15 \%$ higher total BMD (The highest value of total BMD was $1.59 \mathrm{~g} / \mathrm{cm}^{2}$ ). Moreover, there were significant correlations between body weight and total BMD in all subjects. As predicted from regression analysis in the case of $200 \mathrm{~kg}$ body weight, the calculated total BMD was $1.42 \mathrm{~g} / \mathrm{cm}^{2}$. Although the recent study reported that the collegiate American football player with $135.5 \mathrm{~kg}$ mean body weight had the mean and max values of 1.63 and $2.11 \mathrm{~g} / \mathrm{cm}^{2}$ total BMD using iDXA (Prodigy GE Healthcare Lunar ${ }^{11}$, it was speculated that the upper limit of total BMD in human with $150 \mathrm{~kg}$ bodyweight might be around $1.60 \mathrm{~g} / \mathrm{cm}^{2}$ when using DXA manufactured by Hologic Inc.

In the present study, BMD in legs is significantly different between middle and heavyweight Sumo wrestlers, but not in arms. (Table 2). In addition, although BMD in arms was not correlated with body weight, fat mass, and LSTM, BMD in legs was significantly related to body weight and LSTM (Table 3). These results suggested that BMD in the legs might receive a larger load and mechanical stress through daily living and exercise compared to the BMD in arms. Especially, it is speculated that the specific Sumo wrestling training such as stamping with a heavy body mass is more effective for the BMD in legs.

Sumo wrestlers have large masses of SM, liver, kidneys, and heart ${ }^{6,7}$. Similarly, this study found that Sumo wrestlers had a greater BMC and BMD from the comparison of previous studies, although the present study was a lack of controls. On the other side, the present study indicates that BMC and BMD might not sharply elevate among even heavyweight athletes.

\section{Abbreviations}

BMC: bone mineral contents; BMD: bone mineral density; BMI: body mass index; DXA: dual-energy X-ray absorptiometry; FFM: fat-free mass; LSTM: lean soft tissue mass; SM: skeletal muscle.

\section{Declarations}

\section{Competing interests}

No other authors declare competing interests. 


\section{Author contributions}

T. M. designed and conducted the research, obtained the data, statistically analyzed the whole data set, and wrote the paper. S.T., M.O., and S.S. obtained the data and reviewed the paper.

\section{Acknowledgments:}

We sincerely thank the subjects who participated in this study. This study was supported by the Japan Society for the Promotion of Science KAKENHI Grant No. 24680069.

The datasets used and/or analyzed during the current study are available from the corresponding author on reasonable request.

\section{References}

1. Beekley, M. D., Abe, T., Kondo, M., Midorikawa, T. \& Yamauchi, T. Comparison of normalized maximum aerobic capacity and body composition of sumo wrestlers to athletes in combat and other sports. J. Sports. Sci. Med, 5, 13-20 (2006).

2. Midorikawa, T., Kondo, M., Sakamoto, S. I. I. I. \& Sports and nutrition, 12. Sumo Wrestling. Nutrition and enhanced sports performance -muscle building, endurance, and strength-. Bagchi D, Nair S, Sen C, editors. Academic Press. 129-132(2018).

3. Kondo, M., Abe, T., Ikegawa, S., Kawakami, Y. \& Fukunaga, T. Upper limit of fat-free mass in humans: a study on Japanese Sumo wrestlers. Am. J. Hum. Biol, 6, 613-618 (1994).

4. Midorikawa, T., Sekiguchi, O., Beekley, M. D., Bemben, M. G. \& Abe, T. A comparison of organ-tissue level body composition between college-age male athletes and nonathletes. Int. J. Sports. Med, 28, 100-105 (2007).

5. Abe, T., Kearns, C. F. \& Fukunaga, T. Sex differences in whole body skeletal muscle mass measured by magnetic resonance imaging and its distribution in young Japanese adults. Br. J. Sports. Med, 37, 436-440 (2003).

6. Midorikawa, T., Kondo, M., Beekley, M. D., Koizumi, K. \& Abe, T. High REE in Sumo wrestlers attributed to large organ-tissue mass. Med Sci Sports Exerc, 39, 688-693 (2007).

7. Kinoshita, N. et al. Unusual left ventricular dilatation without functional or biochemical impairment in normotensive extremely overweight Japanese professional sumo wrestlers. Am. J. Cardiol, 91, 699703 (2003).

8. Kohrt, W. M., Bloomfield, S. A., Little, K. D., Nelson, M. E. \& Yingling, V. R. American College of Sports Medicine. American College of Sports Medicine Position Stand: physical activity and bone health. Med. Sci. Sports. Exerc, 36, 1985-1996 (2004).

9. Ito, H. et al. Relation between body composition and age in healthy Japanese subjects. Eur. J. Clin. Nutr, 55, 462-470 (2001).

10. Antonio, J. et al. Bone Mineral Density in Competitive Athletes. J. Exerc. Nutr, 1, 1-11 (2018). 
11. Bosch, T. A., Carbuhn, A. F. \& Stanforth, P. R. Body composition and bone mineral density of division 1 collegiate football players: A consortium of college athlete research study. J. Strength. Cond. Res, 33, 1339-1346 (2019).

12. Andreoli, A. et al. Effects of different sports on bone density and muscle mass in highly trained athletes. Med. Sci. Sports. Exerc, 33, 507-511 (2001).

13. Fredericson, M. et al. Regional bone mineral density in male athletes: a comparison of soccer players, runners and controls. Br. J. Sports. Med, 41, 664-668 (2007).

\section{Figures}




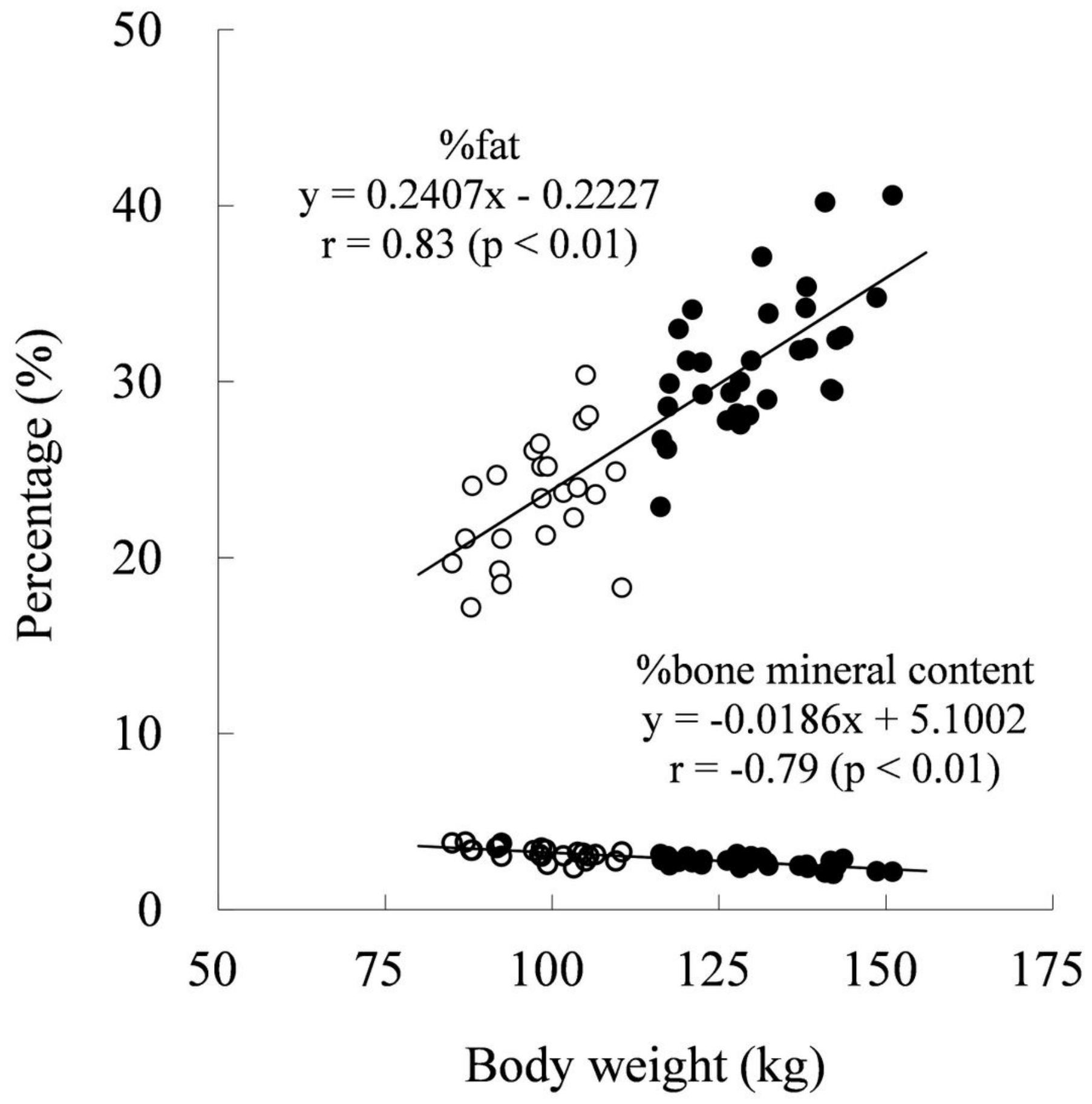

Figure 1

Relationships of body weight with the percentages of body fat and bone mineral contents. $\mathbf{0}$ : middleweight Sumo wrestlers, $\mathbf{0}$ : heavyweight Sumo wrestlers 